\title{
Generation of mouse lines with conditionally or constitutively inactivated Snca gene and Rosa26-stop-lacZ reporter located in cis on the mouse chromosome 6
}

\author{
Andrei Yu. Roman • Galina Limorenko • Alexey A. Ustyugov • Tatiana V. Tarasova • \\ Ekaterina A. Lysikova • Vladimir L. Buchman • Natalia Ninkina $(\mathbb{D}$
}

Received: 21 July 2016/Accepted: 31 October 2016/Published online: 12 November 2016

(C) The Author(s) 2016. This article is published with open access at Springerlink.com

\begin{abstract}
Synuclein is involved in many important molecular processes in neuronal cells and their synapses, and its malfunction has been linked to the development of Parkinson's and certain other neurodegenerative diseases. Animal models allowing tightly monitored conditional inactivation of the encoding gene, Snca, are indispensible for studies aimed at understanding normal function of $\alpha$-synuclein in various neuronal populations and its role in pathogenesis of neurodegenerative diseases. We have recently reported the production of several novel mouse lines for manipulating expression of the endogenous Snca gene, including a line for Crerecombinase-driven conditional inactivation of the gene (mice with floxed Snca) and a new line with a constitutive knockout of $\alpha$-synuclein. Rosa26-stoplacZ reporter cassette is commonly used for
\end{abstract}

A. Yu. Roman · A. A. Ustyugov - T. V. Tarasova .

E. A. Lysikova · V. L. Buchman · N. Ninkina Institute of Physiologically Active Compounds, Russian Academy of Sciences, 1 Severniy proezd, Chernogolovka, Moscow Region, Russian Federation 142432

A. Yu. Roman

Inserm, CRO2 UMR_S 911, Faculté de Pharmacie, AixMarseille Université, 13385 Marseille, France

G. Limorenko - T. V. Tarasova · V. L. Buchman .

N. Ninkina $(\bowtie)$

School of Biosciences, Cardiff University, Museum

Avenue, Cardiff CF10 3AX, UK

e-mail: ninkinan@cf.ac.uk monitoring efficiency of Cre-recombination but in mouse genome Snca and Rosa26 loci are located on the same chromosome. Here we describe production of lines with a modified Snca locus, either floxed or constitutively inactivated and the Rosa26-stop-lacZ reporter cassette located in cis on the mouse chromosome 6 . These new mouse lines are invaluable for fast identification of cells with inactivation of Snca by Crerecombination and represent useful tools for in vivo studies of $\alpha$-synuclein function and dysfunction.

Keywords Synuclein - Conditional gene knockout · Meiotic recombination - Transgenic mice - LoxP/Cre recombination

\section{Introduction}

Several missense mutations altering physico-chemical properties of $\alpha$-synuclein as well as increased production of $\alpha$-synuclein caused by duplications and triplications of the genomic region containing encoding gene, SNCA, have been associated with the development of familial forms of Parkinson's disease (PD) and related disorders (Polymeropoulos et al. 1997; Kruger et al. 1998; Singleton et al. 2003; Zarranz et al. 2004; ChartierHarlin et al. 2004; Ibanez et al. 2004; Proukakis et al. 2013; Appel-Cresswell et al. 2013; Kiely et al. 2013; Lesage et al. 2013). Moreover, Lewy bodies and Lewy neurites, histopathological hallmarks of both hereditary 
and idiopathic forms of PD, are built on a scaffold of aggregated and fibrillated $\alpha$-synuclein (Spillantini et al. 1997, 1998). Genome-wide associated and case-control studies also linked $\alpha$-synuclein to idiopathic and familial forms of PD as well as other synucleinopathies (Kay et al. 2008; Mizuta et al. 2008; Pankratz et al. 2009; Scholz et al. 2009; Sutherland et al. 2009).

It is still not clear how altered $\alpha$-synuclein metabolism triggers the development of pathological changes in these neurodegenerative diseases. The gainof-function hypothesis is based on multiple evidence of the toxicity of intermediate products of $\alpha$-synuclein aggregation, oligomers and protofibrils. However, $\alpha-$ synuclein is important for structural and functional integrity of vertebrate neurons and/or their synapses (reviewed in Venda et al. 2010) and pathological aggregation of this protein might cause significant depletion of its functional pool in neurons and particularly in presynaptic terminals. Therefore, a contribution of $\alpha$-synuclein loss-of-function mechanism to molecular pathogenesis of synucleinopathies cannot be discounted, despite no obvious signs of neurodegeneration have been observed in studies of constitutive $\alpha$-synuclein knockout mice [reviewed in Buchman and Ninkina (2008)]. These discouraging results can be explained by efficient mechanisms compensating to the loss of $\alpha$-synuclein. It has been suggested that this compensation takes place in the developing nervous system during a period of its high plasticity (Al-Wandi et al. 2010). Depletion of $\alpha$-synuclein in adult or ageing nervous system might be significantly more deleterious. To test this hypothesis an experimental system allowing conditional inactivation of $\alpha$-synuclein encoding gene is required. Moreover, such system would be invaluable for assessing $\alpha$-synuclein function in specific neuronal populations as well as in studies of $\alpha$-synuclein aggregation pathology propagation through the nervous system.

Conditional gene knockout in mice requires a core mouse line with the gene of interest or its fragment surrounded by recognition sites for certain specific recombinases, most commonly Cre or FRT, and a transgenic mouse line expressing this recombinase in the particular type of cells. It is important to monitor the efficiency and specificity of recombination and to achieve this a reporter gene whose activation by a recombination event driven by the same enzyme can be easily detected, is also introduced in the animal genome. For monitoring Cre-loxP recombination a
Rosa26-stop-lacZ reporter cassette is widely used. This reporter is usually delivered by another mouse line carrying a loxP-flanked transcription STOP sequence, which prevents expression of the downstream bacterial lac $Z$ gene encoding $\beta$-galactosidase (Soriano 1999). Activation of Cre-recombinase in a cell carrying both the reporter and the floxed gene of interest leads to simultaneous deletion of both floxed genomic fragments leading to inactivation of the studied gene and activation of lac $Z$ expression, the latter can be readily detected due to accumulation of a colored product of $\beta$-galactosidase activity in cells when specific substrates are added to tissue samples.

We intended to use the Rosa26-stop-lacZ reporter to monitor conditional inactivation of $\alpha$-synuclein coding gene (Snca) in mice carrying this gene with loxP-flanked first coding exon [Snca ${ }^{\text {flox }}$ ] (Ninkina et al. 2015) and tamoxifen-activated Cre-recombinase (Cre/ ERT2) under control of various neuron-specific promoters but this was obscured by co-localisation of Snca and ROSA26 loci on the same mouse chromosome 6 . To overcome this obstacle we have previously produced and used a mouse line with Rosa26-stoplacZ cassette and permanently inactivated Snca gene (Abeliovich et al. 2000) located on the same chromosome in cis. Here we describe a similar line but with a version of permanent Snca gene knockout that lack problems associated with the presence of Neo cassette in the genome of mice produced by Abeliovich et al. (2000), for example dramatic overexpression of Mmrn1 gene (Ninkina et al. 2015). We also produced a mouse line that carries Snca ${ }^{\text {flox }}$ gene and Rosa26stop-lacZ reporter cassette located in cis at the mouse chromosome 6 . These lines represent useful tools for production of large cohorts of experimental animals for conditional inactivation of $\alpha$-synuclein function.

\section{Materials and methods}

\section{Animals}

All animals were on C57B16J genetic background. Animal work was carried out in accordance with the United Kingdom (Scientific Procedures) Act (1986) and European Directive EC 86/609, and has been approved by the Cardiff University Ethical Review Committee and the Home Office (Project Licence 30/2844). The core mouse line for conditional 


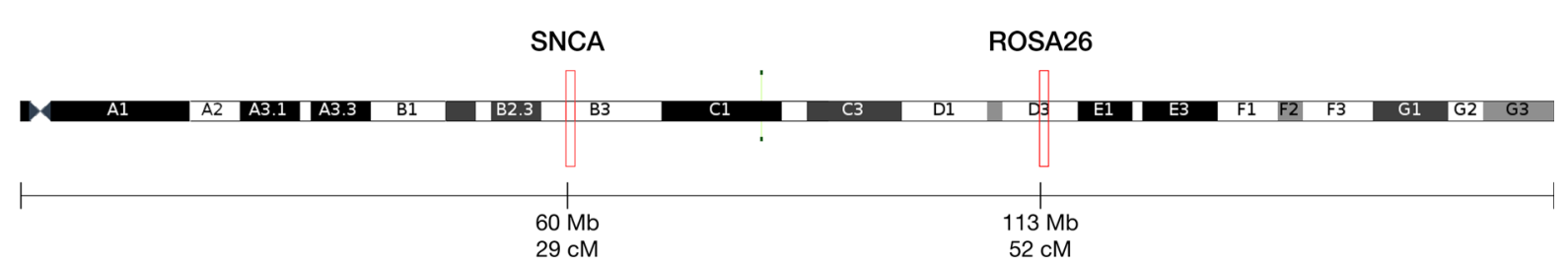

Fig. 1 Relative positions of Snca and Rosa26 loci on mouse chromosome 6

inactivation of Snca gene, [Snca ${ }^{\text {flox }}$ Rosa26 $6^{w t} /$ $\mathrm{Snca}^{+}{ }_{2}$ Rosa26 $6^{w t}$ ], has been deposited to and now available from The Jackson Laboratory (C57BL/6Snca $<$ tm1.1Vlb $>$ J; JAX Stock\#025636).

\section{Genotyping}

Genomic DNA was isolated from mouse ear biopsies as described elsewhere (Ninkina et al. 2009). PCR amplification was employed to verify genotypes.

For Rosa26 locus combination of three primers in the reaction (5'-CTTGTGATCCGCCTCGGAGT-3'; $5^{\prime}$-GG CATTCATGGGAGTGGAAA- $3^{\prime} ; 5^{\prime}$-TACTGGCCTGC TCCCTTATC- $3^{\prime}$ ) produced 577 and 450 bp amplification fragments corresponding to wild type and modified alleles, respectively.

For Snca locus combination of three primers in the reaction (5'-TGCTGGGCACAGTGTTGATTG-3'; 5'-AAAGGCTGGGCTTCAAGCAG-3'; 5'-CATGA GTACTTGTGGCTCAC-3') produced amplification fragments of $354 \mathrm{bp}$ for $\mathrm{Snca}^{+}, 280 \mathrm{bp}$ for $\mathrm{Snca}^{-}$and 406 bp for $S n c a^{\text {flox }}$ alleles, respectively.

For both amplification reactions $94{ }^{\circ} \mathrm{C}$ for $2 \mathrm{~min}$ followed by 45 cycles of $94{ }^{\circ} \mathrm{C}$ for $15 \mathrm{~s}, 60{ }^{\circ} \mathrm{C}$ for $20 \mathrm{~s}$ and $72{ }^{\circ} \mathrm{C}$ for $30 \mathrm{~s}$ were used.

Western blot analysis

Total protein extraction from mouse neuronal tissues, SDSPAGE separation, semi-dry transfer, blocking, incubation with antibodies, washing and detection using enhanced chemiluminescence were carried out as described previously (Anwar et al. 2011). Antibodies against $\alpha$-synuclein (mouse monoclonal, clone 42, BD Transduction Laboratories, diluted 1:500) and $\beta$-actin (mouse monoclonal, clone AC-15, Sigma diluted 1:5000) were used.

Detection of $\beta$-galactosidase activity in brain slices

$\left[\right.$ Snca ${ }^{\text {flox }} \_$Rosa26 $6^{\text {mod }} /$ Snca ${ }^{\text {flox }}$ Rosa26 $\left.6^{\text {mod }}\right]$ mice were crossed with transgenic mice expressing Cre-ERT2 under control of neurospecific NSE promoter (obtained from Jean C. Manson, The Roslin Institute, University of Edinburgh) and at the age of 3 month resulting F1 animals were injected intraperitoneally with tamoxifen (Sigma-Aldrich) dissolved in corn oil for five consecutive days (daily dose $75 \mathrm{mg} / \mathrm{kg}$ ). One month after activation of Cre recombination by tamoxifen brains were dissected and transverse slices ( $\sim 1 \mathrm{~mm}$ thick) through the brainstem were processed and stained for $\beta$-galactosidase activity using $\mathrm{X}$-gal as a substrate as described elsewhere (Burn 2012).

\section{Results and discussion}

Within our previous breeding programme a mouse founder has been obtained that carried a permanently inactivated Snca locus from mice originally produced by Abeliovich et al. (2000) and Rosa26-stop-lacZ cassette (Soriano 1999) on the same chromosome 6 in cis. As the physical distance between Snca and Rosa26 loci is $52.3 \mathrm{Mb}$, which constitutes more than one-third of total $150 \mathrm{Mb}$ length of mouse chromosome 6 (Fig. 1), and genetic distance is $23.5 \mathrm{cM}$, high meiotic recombination frequency between these loci is expected. Therefore we decided to carry out additional breeding programme aimed for obtaining mouse lines carrying other genetic modifications of Snca gene in cis with Rosa26-stop-lacZ reporter cassette.

The deletion of the Snca exon 2 (first coding exon) by Cre-loxP recombination in the germline causes complete arrest of $\alpha$-synuclein production in homozygous $\mathrm{Snca}^{-} / \mathrm{Snca}^{-}$mice. This genomic modification does not affect expression of neighboring genes, e.g. Mmrn1 (Ninkina et al. 2015), which is a drawback for the knockout mice produced by Abeliovich et al. Mice homozygous for this Cre-induced deletion, [Snca ${ }^{-}$--

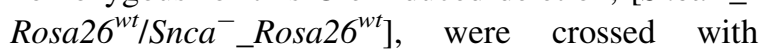
homozygous mice bearing Rosa26-stop-lacZ cassette, $\left[\mathrm{Snca}^{+}{ }_{-} \mathrm{Rosa}_{26} 6^{\text {mod }} / \mathrm{Snca}^{+}{ }_{2}\right.$ Rosa $\left.26^{\text {mod }}\right]$, and resulting $\mathrm{F} 1$ offsprings of $\left[\mathrm{Snca}^{+}{ }_{-}\right.$Rosa $\left.26^{\text {mod }} / \mathrm{Snca}^{-}{ }_{-} \mathrm{Rosa}_{2} 6^{\mathrm{wt}}\right]$ 
A

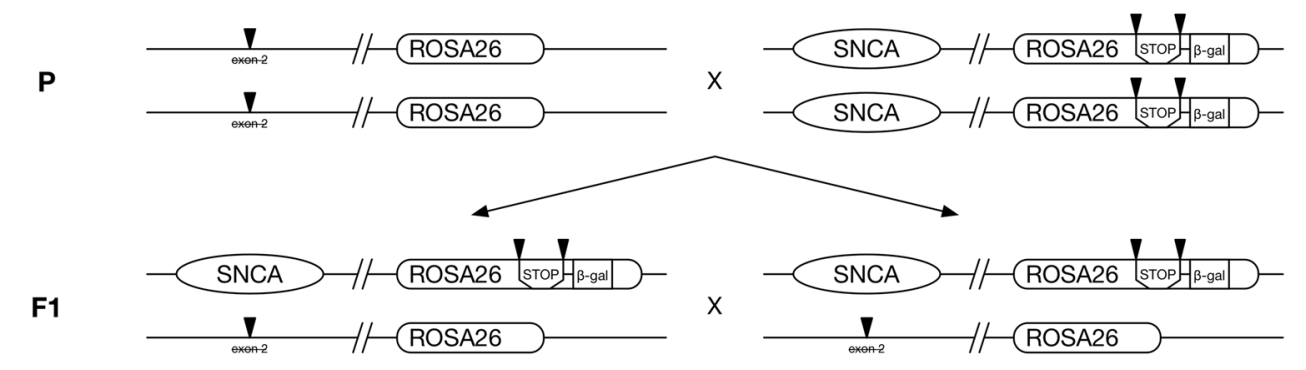

F2
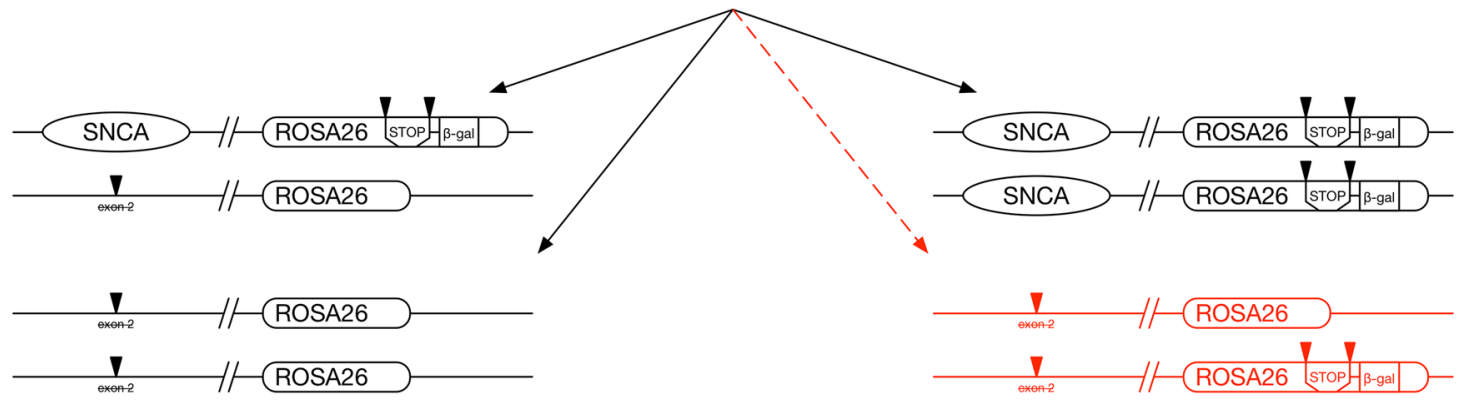

B
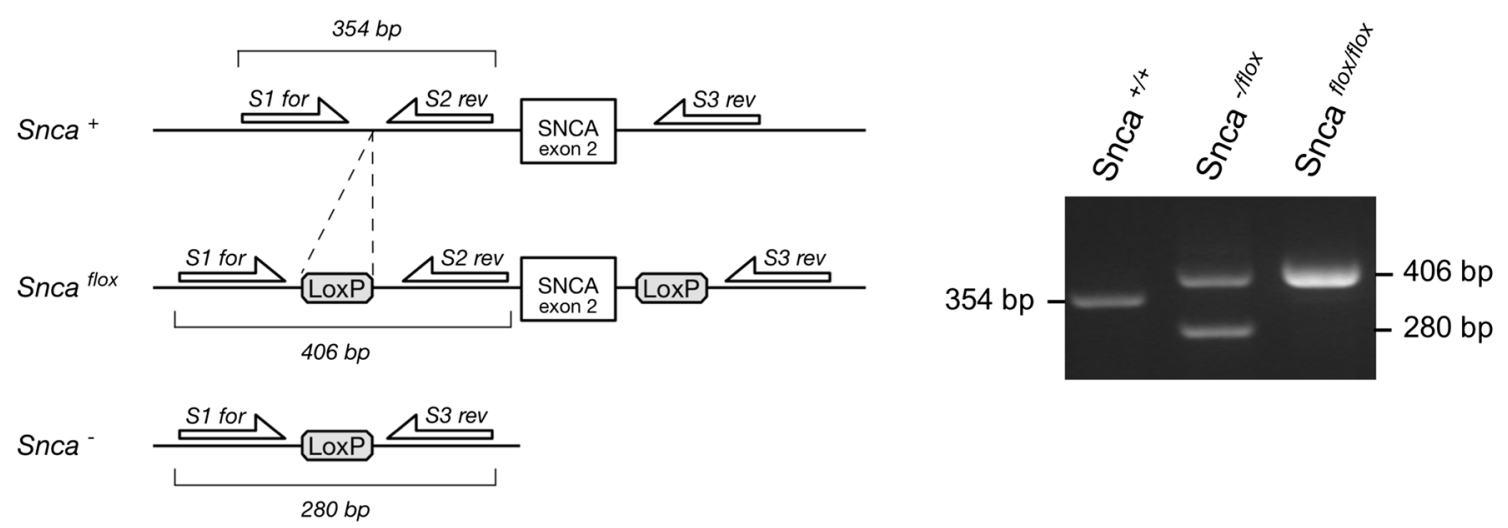

C
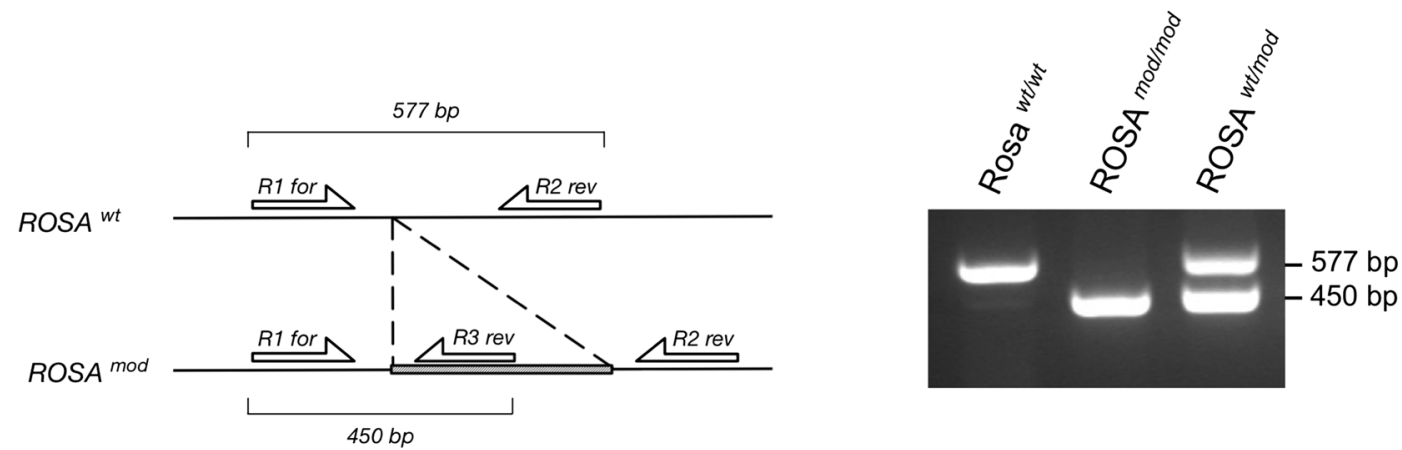

Fig. 2 A sheme of the breeding protocol that produced mouse founders carrying a constituent knock-out of $\alpha$-synuclein-

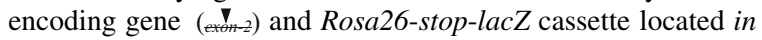
cis on mouse chromosome 6 as the result of meiotic recombination (a). PCR amplification approach used for identification of modifications in Snca (b) and Rosa26 (c) loci. Position of primers within these loci and analysis of corresponding amplification products in agarose gel are shown 


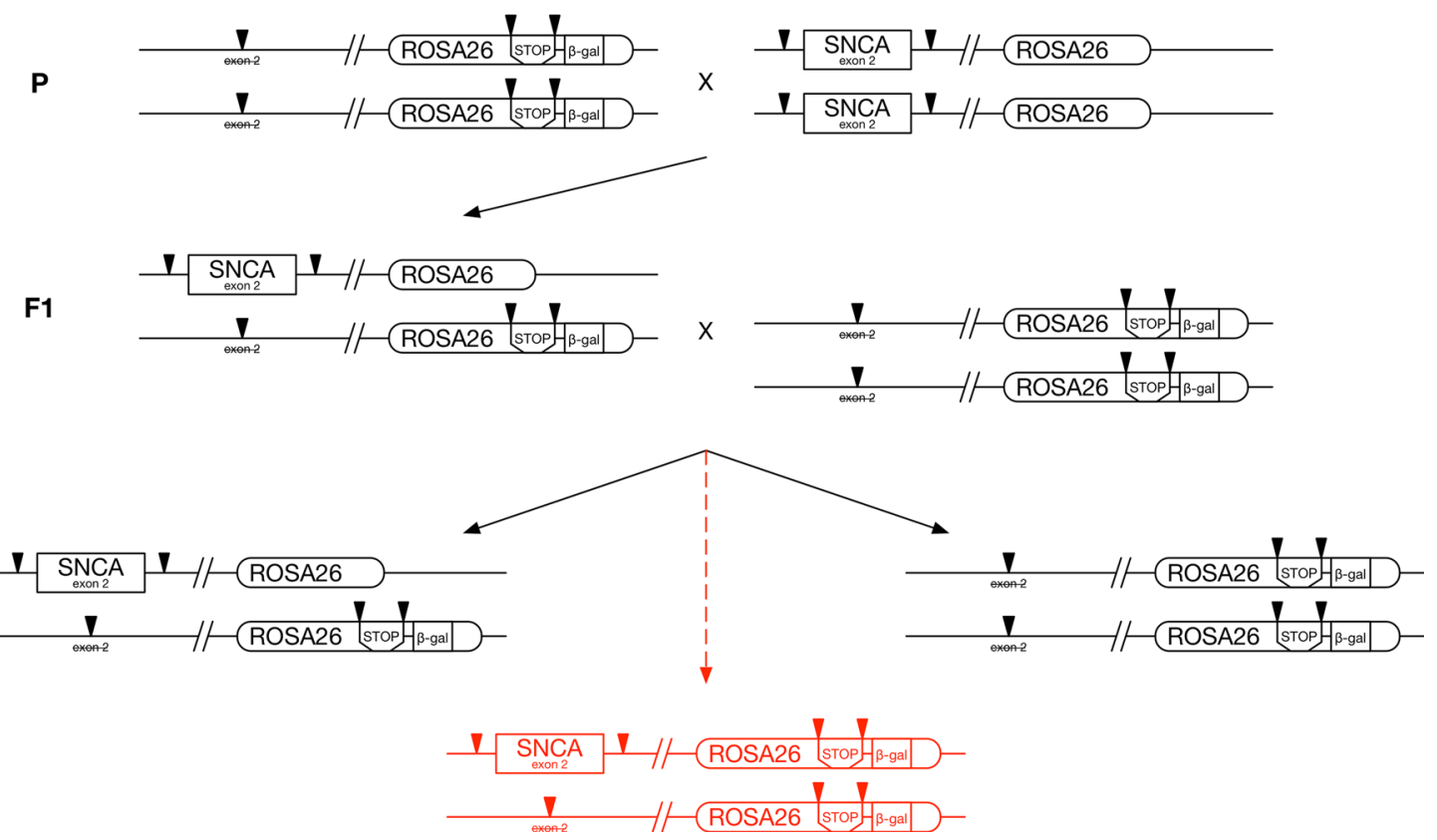

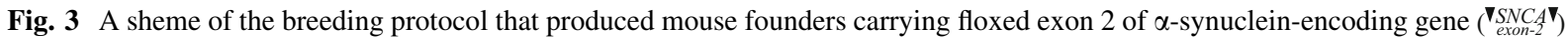
and Rosa26-stop-lacZ cassette located in cis on mouse chromosome 6 as the result of meiotic recombination

genotype were intercrossed (Fig. 2a). F2 offsprings were genotyped for both loci (Fig. 2b, c). Between 26 analysed animals one displayed genotype $\left[\mathrm{Snca}^{-}{ }_{-}^{-}\right.$ ${\text { Rosa } 26^{\text {mod }} / \mathrm{Snca}^{-} \text {_Rosa26 }}^{\text {wt }}$ ] (shown in red in Fig. 2a), which was not consistent with classical Mendelian inheritance that predicts segregation of chromosomes and independent assortment of alleles. Most probably this genotype appeared as a result of a reciprocal recombination between chromosome 6 bearing Rosa26-stop-lacZ cassette and chromosome 6 bearing Snca null mutant gene during meiosis I phase of gametogenesis leading to non-Mendelian segregation of traits. Consequently, a male mouse that became a founder of a new line carried a chromosome 6 with both $\mathrm{Snca}^{-}$and Rosa26 ${ }^{\text {mod }}$ loci in cis. Further backcrossing and intercrossing produced a line of homozygous $\left[\mathrm{Snca}^{-}{ }_{\text {Rosa } 26^{\text {mod }} / \mathrm{Snca}^{-}{ }_{-} \text {Rosa26 }}{ }^{\text {mod }}\right]$ mice.

These homozygous mice were further crossed with homozygous mice of the core line for conditional inactivation of $\alpha$-synuclein-encoding gene, [Snca flox/ Snca $\left.{ }^{f l o x}\right]$, that have the second exon of Snca gene flanked with loxP sites in direct orientation. F1 offspring heterozygous for both Snca and Rosa26 loci, [Snca ${ }_{-}$Rosa26 $6^{\text {mod }} /$ Snca ${ }^{\text {flox }}{ }_{-}$Rosa26 $\left.6^{\text {wt }}\right]$, were crossed again with homozygous $\left[\mathrm{Snca}^{-}{ }_{-} \mathrm{Rosa}_{2} 6^{\text {mod/ }}\right.$
Snca ${ }^{-}{ }_{-}$Rosa $26^{\text {mod }}$ ], the Rosa26 genotype of the offspring was analysed and animals carrying Rosa26stop-lacZ cassette on both chromosomes were selected for further analysis. Snca genotypes were assessed for 130 of these F2 mice and although majority of animals displayed either of two expected Mendelian genotypes, a $\left[\mathrm{Snca}^{-} \_\right.$Rosa26 $6^{\text {mod }} /$ Snca $^{\text {flox }}{ }_{-}$Rosa $\left.26^{\text {mod }}\right]$ genotype (shown in red in Fig. 3), was revealed in 11 animals.

Meiotic recombination frequency between these two loci seems higher during oogenesis than during spermatogenesis as crosses that involved female F1

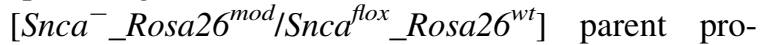
duces 7 F2 [Snca ${ }^{-}$Rosa26 $6^{\text {mod }} /$ Snca ${ }^{\text {flox }}{ }_{-}$Rosa2 $\left.6^{\text {mod }}\right]$ animals from total 64 homozygous Rosa $26^{\text {mod }}$ animals, whereas for crosses that involved male F1

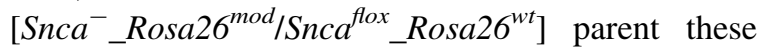
numbers were 4 from 67 . Although these results are not statistically significant with the number of animals assessed ( $p>0.05$, Chi-square test) it might still be taken into consideration when experimental cohorts are generated using a breeding programme with meiotic recombination between these loci is possible but not desired.

Male and female $\left[\mathrm{Snca}^{-}{ }_{-}\right.$Rosa $26^{\text {mod }} /$ Snca $^{\text {flox }}$ Rosa $26^{\text {mod }}$ ] founders were intercrossed to produce 

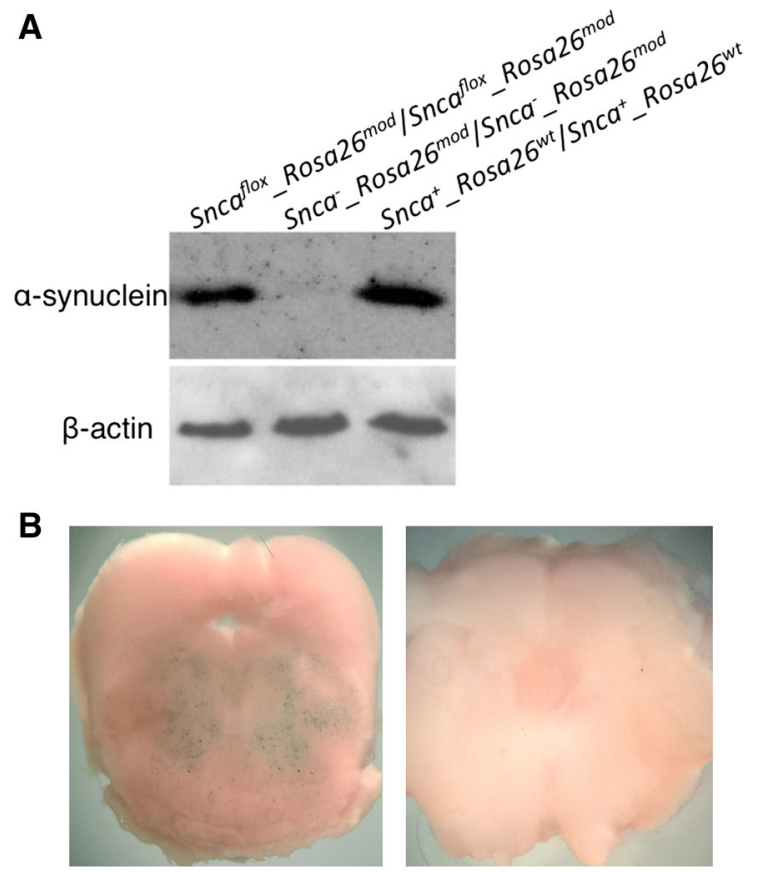

+ tamoxifen

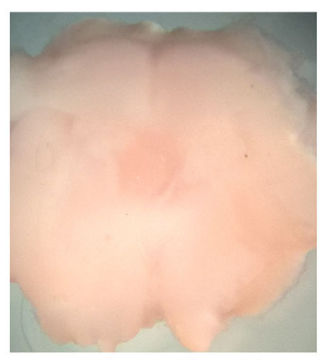

- tamoxifen

Fig. 4 Western blot analysis of $\alpha$-synuclein expression in the brainstem of mice obtained in this study (a) and detection of $\beta$ galactosidase activity using $\mathrm{X}$-gal staining in transverse slices

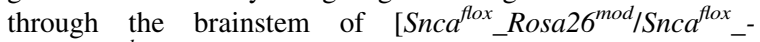
Rosa2 $6^{\text {mod }}$ ] mice following tamoxifen-induced activation of Cre-ERT2 recombinase in neurons (b)

homozygous [Snca ${ }^{\text {flox }}$ Rosa $26^{\text {mod }} /$ Snca $^{\text {flox }}{ }_{-}$ Rosa $26^{\text {mod }}$ ] animals that were further used for establish a new mouse line.

In this mouse line expression of $\alpha$-synuclein in neuronal tissues was the same as in wild type, $\left[\mathrm{Snca}^{+} \_\right.$Rosa $\left.26^{w t} / \mathrm{Snca}^{+}{ }_{\text {Rosa } 26^{w t}}\right], \quad$ animals, whereas no $\alpha$-synuclein was detected in neuronal tissues of the new knockout, [Snca ${ }^{-}$Rosa26 $6^{\text {mod }}$ / Snca ${ }^{-}$Rosa26 $6^{\text {mod }}$ ], mice (Fig. 4a). As expected, activation of Cre-recombinase in neurons of [Snca flox Rosa $26^{\text {mod }} /$ Snca $^{\text {flox }}$ Rosa $26^{\text {mod }}$ ] mice led to expression of lacZ gene from the modified Rosa26 locus (Fig. 4b).

Two new transgenic mouse lines produced in this study complement a set of previously described mouse lines (Ninkina et al. 2015) for manipulating endogenous $\alpha$-synuclein expression and makes generation of experimental cohorts for experiments required conditional inactivation of $\alpha$-synuclein function relatively easy and straightforward.

For example, it is sufficient to obtain mice carrying a copy of relevant Cre-recombinase along with a copy of $S n c a^{f l o x}$ allele, i.e. $\left[S n c a^{f l o x} R_{R o s a} 26^{w t} / S n c a^{+}\right.$Rosa $\left.26^{w t}\right]$, and cross them with [Snca ${ }^{\text {flox }}$ Rosa $26^{\text {mod }}$ / Snca ${ }^{\text {flox }}$ Rosa26 $6^{\text {mod }}$ ] mice to obtain experimental cohorts, i.e. Cre-positive [Snca ${ }^{\text {flox }}$ Rosa26 $6^{\text {mod }}$, Snca ${ }^{\text {flox }}$ Rosa $26^{w t}$ ] mice, and various control cohorts,

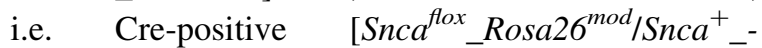
Rosa26 $6^{w t}$ ] mice that will retain one functional copy of Snca gene even after Cre-recombination takes place, and Cre-negative mice either homozygous or heterozygous for Snca gene. Alternatively, Cre-posi-

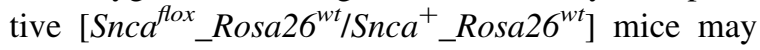
be crossed with another line described here, [Snca ${ }^{-}$Rosa $26^{\text {mod }} / \mathrm{Snca}^{-}$_Rosa26 $\left.6^{\text {mod }}\right]$ mice, to obtain Crepositive heterozygous Snca experimental, [Snca ${ }^{\text {flox }}$ Rosa $26^{\text {wt }} / \mathrm{Snca}^{-}$_Rosa26 $6^{\text {mod }}$ ] and Cre-positive heterozygous Snca control, [Snca ${ }^{+}{\text {Rosa } 26^{w t} /}$ Snca ${ }^{-}$_Rosa $26^{\text {mod }}$ ] mice.

Moreover, the [Snca ${ }^{\text {flox }}$ Rosa $26^{\text {mod }} /$ Snca $^{\text {flox }}$ Rosa26 $6^{\text {mod }}$ ] line is an obvious choice for experiments with non-genetic delivery of Cre-recombinase for local inactivation of Snca gene, e.g. stereotaxic injection of recombinant viruses expressing this enzyme, or for preparing primary neuronal cultures and consequent inactivation of Snca gene by transfection or viral transduction of Cre-expressing constructs.

In conclusion, we produced two mouse lines that constitute novel useful tools for studying normal function of $\alpha$-synuclein and its role in pathological processes.

Acknowledgements This study was supported by State Contract No. 14.604.21.0144 from Ministry of Education and Science of the Russian Federation (identification RFMEFI60414X0144). We are grateful to Jean C. Manson for a kind gift of the NSE-Cre/ER-T2 mouse line.

Open Access This article is distributed under the terms of the Creative Commons Attribution 4.0 International License (http:// creativecommons.org/licenses/by/4.0/), which permits unrestricted use, distribution, and reproduction in any medium, provided you give appropriate credit to the original author(s) and the source, provide a link to the Creative Commons license, and indicate if changes were made.

\section{References}

Abeliovich A et al (2000) Mice lacking alpha-synuclein display functional deficits in the nigrostriatal dopamine system. Neuron 25:239-252 
Al-Wandi A, Ninkina N, Millership S, Williamson SJ, Jones PA, Buchman VL (2010) Absence of alpha-synuclein affects dopamine metabolism and synaptic markers in the striatum of aging mice. Neurobiol Aging 31:796-804

Anwar S et al (2011) Functional alterations to the nigrostriatal system in mice lacking all three members of the synuclein family. J Neurosci 31:7264-7274

Appel-Cresswell S et al (2013) Alpha-synuclein p. H50Q, a novel pathogenic mutation for Parkinson's disease. Mov Disord 28:811-813

Buchman VL, Ninkina N (2008) Modulation of alpha-synuclein expression in transgenic animals for modelling synucleinopathies-is the juice worth the squeeze? Neurotox Res 14:329-341

Burn SF (2012) Detection of $\beta$-galactosidase activity: X-gal staining. Methods Mol Biol 886:241-250

Chartier-Harlin MC et al (2004) Alpha-synuclein locus duplication as a cause of familial Parkinson's disease. Lancet 364:1167-1169

Ibanez P et al (2004) Causal relation between alpha-synuclein gene duplication and familial Parkinson's disease. Lancet 364:1169-1171

Kay DM et al (2008) Genetic association between alpha-synuclein and idiopathic Parkinson's disease. Am J Med Genet B Neuropsychiatr Genet 147B:1222-1230

Kiely AP et al (2013) Alpha-synucleinopathy associated with G51D SNCA mutation: a link between Parkinson's disease and multiple system atrophy? Acta Neuropathol 125:753-769

Kruger R et al (1998) Ala30Pro mutation in the gene encoding alpha-synuclein in Parkinson's disease. Nat Genet 18:106-108

Lesage $\mathrm{S}$ et al (2013) G51D alpha-synuclein mutation causes a novel parkinsonian-pyramidal syndrome. Ann Neurol 73:459-471

Mizuta I et al (2008) Calbindin 1, fibroblast growth factor 20, and alpha-synuclein in sporadic Parkinson's disease. Hum Genet 124:89-94

Ninkina N, Peters O, Millership S, Salem H, van der Putten H, Buchman VL (2009) Gamma-synucleinopathy: neurodegeneration associated with overexpression of the mouse protein. Hum Mol Genet 18:1779-1794
Ninkina N, Connor-Robson N, Ustyugov AA, Tarasova TV, Shelkovnikova TA, Buchman VL (2015) A novel resource for studying function and dysfunction of alpha-synuclein: mouse lines for modulation of endogenous Snca gene expression. Sci Rep 5:16615

Pankratz N et al (2009) Genomewide association study for susceptibility genes contributing to familial Parkinson disease. Hum Genet 124:593-605

Polymeropoulos MH et al (1997) Mutation in the alpha-synuclein gene identified in families with Parkinson's disease. Science 276:2045-2047

Proukakis C et al (2013) A novel alpha-synuclein missense mutation in Parkinson disease. Neurology 80:1062-1064

Scholz SW et al (2009) SNCA variants are associated with increased risk for multiple system atrophy. Ann Neurol 65:610-614

Singleton AB et al (2003) Alpha-synuclein locus triplication causes Parkinson's disease. Science 302:841

Soriano P (1999) Generalized lacZ expression with the ROSA26 Cre reporter strain. Nat Genet 21:70-71

Spillantini MG, Schmidt ML, Lee VM, Trojanowski JQ, Jakes R, Goedert M (1997) Alpha-synuclein in Lewy bodies. Nature 388:839-840

Spillantini MG, Crowther RA, Jakes R, Hasegawa M, Goedert M (1998) Alpha-synuclein in filamentous inclusions of Lewy bodies from Parkinson's disease and dementia with Lewy bodies. Proc Natl Acad Sci USA 95:6469-6473

Sutherland GT et al (2009) Do polymorphisms in the familial Parkinsonism genes contribute to risk for sporadic Parkinson's disease? Mov Disord 24:833-838

Venda LL, Cragg SJ, Buchman VL, Wade-Martins R (2010) Alpha-synuclein and dopamine at the crossroads of Parkinson's disease. Trends Neurosci 33:559-568

Zarranz JJ et al (2004) The new mutation, E46K, of alphasynuclein causes Parkinson and Lewy body dementia. Ann Neurol 55:164-173 